\title{
Mechanical properties of carbon nanotube reinforced Epoxy Resin composites
}

\author{
Sinaa I.Husaen* \\ Received 26, October, 2010 \\ Accepted 1, June, 2011
}

\begin{abstract}
:
Overlapped have been prepared from epoxy resin material added to carbon Nanotube and percentages weight $(0.1,0.05,0.01) \%$ Studied the mechanical properties of the composite (bending, tensile an

$\mathrm{d}$ hardness) has been found that the Flexural and tensile modulus of the composites were higher than the pure epoxy resin this may be due to the high mechanical strength of carbon nano tube (CNT).

The hardness of the epoxy carbon Nanotube composites increased and the reason is due to increased overlap and stacking between the additives and material basis, which reduces the movement of polymer molecules leading to increased resistance to scratching material and cutting, will become more resistance to plastic deformation.
\end{abstract}

Key words: - epoxy resin, carbon nanotube, bending test, tensile test, hardness test.

\section{Introduction:-}

Polymer matrix composites
with carbon nanotube reinforcement have become popular in structural applications because of unique atomic structure, very high Aspect

ratio and extraordinary properties like strength and flexibility of CNT [1] . The high bond strength of the constituent carbon-carbon bonds of multi-walled carbon nanotubes (MWNTs) are the reason behind its outstanding mechanical properties. On the other hand, epoxy resins are well established thermosetting matrices of advanced composites, displaying a series of interesting characteristics, which can be adjusted within broad boundaries [2] .They are used as high grade synthetic resins, for example, in the electronics, aeronautics, and astronautics industries. One of the major difficulties encountered during processing of carbon nanotubereinforced epoxy composites is the inability to achieve a uniform dispersion of the nanotubes in the liquid epoxy, since the cured resin is usually friable, their fatigue durability, the thermal stability, and resistance to impact are poor, and the electrical properties are inslouters. Theoretically, the carbon nanotubes addition can improve the mechanical properties and the electrical properties of the epoxy resin greatly, and expand the application of epoxy resin to a larger extent [3]. Smrutisikha [4] studied the Carbon nanotube based epoxy composites have been fabricated at room temperature and refrigeration process using sonication principle. Flexural moduli, electrical conductivity, glass transition temperature of epoxy resin as well as nano composite samples have been determined. Distribution behavior of carbon nanotubes in the epoxy matrix was examined through scanning electron microscopy. Composite 
samples showed better properties than resin samples due to strengthening effect of the filled nanotubes. Allaoui et al [5], Schadler et al[6], Bretonet al[7] have prepared carbon nanotubes/epoxide resin composites by melt mixing method. They have found that carbon nanotubes can improve the mechanical properties of epoxide resin matrix.

\section{The aim of study:-}

The objective of the research is to improve the mechanical properties of epoxy resin using low ratios of carbon nanotube prepared locally.

\section{Materials and Methods:- 1-Carbon nanotubes preparation}

The n-type (111) substrates were thermally oxidized using a thermal evaporation under a pressure $10^{-5}$ bar. The thickness of silicon oxide $\left(\mathrm{SiO}_{2}\right)$ layer was approximately $(300 \mathrm{~nm})$.A $50 \mathrm{~nm}$-thin filim of iron $(\mathrm{Fe})$ was deposited on the top of the $\mathrm{SiO}_{2}$ layer .

The catalyst deposited substrates were loaded on a quartz tube representing the reactor in our CVD system. Argon (Ar) gas was flowed in to a quartz tube CVD oven in order to prevent the oxidation of catalyst film metal while raising the required temperature. For growth CNT s, the temperature was varied between $\left(750-850{ }^{\circ} \mathrm{C}\right)$. The fed gas, acetylene $\left(\mathrm{C}_{2} \mathrm{H}_{2}\right)$ was introduced to the quartz tube after reaching the desired temperature for $10 \mathrm{~min}$. The $\mathrm{CNT}_{\mathrm{S}}$ grown on catalyst particles were examined by atomic forces microscopy (AFM) to measure the diameter and length. The average diameters of the growth CNTS were $7.87 \mathrm{~nm}$. [8]

\section{2- Epoxy resin}

Epoxy resin has been used as a matrix (Master top 123 0 plus), adhesive grade room temperature supplied by Iranian BASF construction chemical. The ratio of hardener to epoxy used in this study was approximately 1:2.

\section{3-Sample preparation:-}

Hand Lay-up technique has been used to prepare sheets of composites. Amount of Epoxy was mixed with carbon nanotube in different weight percentage $(0.01,0.050 .1) \%$ by weight the samples. The dimensions and of cavities were made according to the size and shape of the samples as per ASTM D790 [9] standards for bending test, according to ANSI/ASTM D638 [9], for tensile testing, and ASTME10[10], for hardness test.

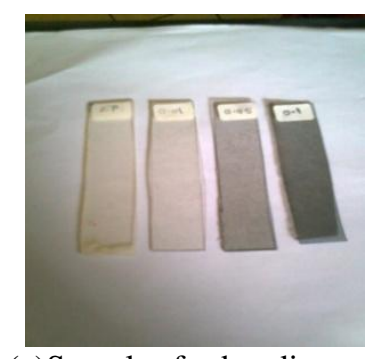

(a)Samples for bending test

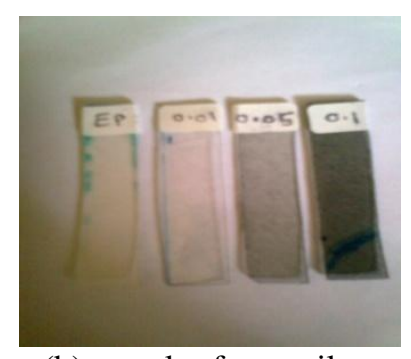

(b) samples for tensile test

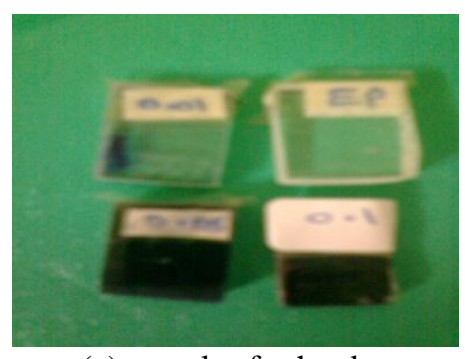

(c) samples for hardness test

\section{4- Measurements:-}

Bending test:- Three point bending test has been used to investeged the mechanism of crack propagation.Instron 1122 was used and the cross head speed were fixed $(1 \mathrm{~mm} / \mathrm{min})$. load- deflection curves were obtained for different samples. The support span (distance between the supports) was depending on the specimen thickness, the load was applied on a specimen at the middle of support span.For a rectangular sample 
under a load in a three-point bending setup:

$$
\begin{aligned}
& \mathrm{F} . \mathrm{S}=3 \mathrm{PL} / 2 \mathrm{bd}^{2} \quad, \quad \mathrm{E}_{\mathrm{B}}=\mathrm{ML}^{3} \\
& / 4 \mathrm{bd}^{3}
\end{aligned}
$$

F.S:- Flexural strength ......(N/mm $\left.{ }^{2}\right)$,

$\mathbf{E}_{\mathbf{B}:-}$. Flexural modulus ......(Mpa)

P: - The applied load at the highest point of load-deflection curve......(N)

L: - The span length …..(Cm $)$, b: - The width of test specimens $(\mathrm{Cm})$.

d:- The thickness of test specimens......(Cm).

M:-The line of curve load-deflection ( $\mathrm{P}(\mathrm{N})$ $\mathrm{D}(\mathrm{Cm}))$

Tensile test: - Instron tensile test machine has been used to measure tensile of the samples, the load was applied on a specimen $(50 \mathrm{KN})$ and speed $(5 \mathrm{~mm} / \mathrm{min})$. The machine is designed to elongate the specimen at a constant rate, and to continuously and simultaneously measure the instantaneous applied load and the resulting elongations using an extensometer.

Hardness test:-It was measured hardness of the samples in a manner shore(D) and the device used for this test type(shore D Hardness tester TH 210) that is a tool that stitches in needle the surface of the sample and then register the number which comes out on the screen of the device .

\section{Results and Discussion:-}

\section{1- Bending test :-}

Flexural modulus of pure resin was found to be $23 \mathrm{MPa}$ as shown in Table (1). The composite samples show greater modulus than pure resin samples $(29,34$, and $48 \mathrm{MPa})$. This may be due to the high mechanical strength of CNT. To matrix contraction of matrix that increases frictional force between nanotubes and epoxy matrix. Through the following forms(Fig 1) the values of strength bending (the maximum load borne by sample to get final break of the sample).The increases values of strength bending due to increase rates by mass carbon nanotube which means the mechanical properties for polymers from highly.

The Young's modulus is then $\boldsymbol{E}=$ stress/strain $=(F / A \circ) /(\delta / / / \circ) . \quad \mathrm{A}$ molecular solid has a low modulus (usually less than $10 \mathrm{GPa}$ ) since van der Waals bonds are weak (typically $0.1 \mathrm{eV})$, whereas a covalently bonded one (such as graphite, diamond, $\mathrm{SiC}$, BN...) has a high modulus (higher than $100 \mathrm{GPa}$ ). Moreover, in each class of solids (defined by the nature of the bonding) experiments show that elastic constants follow a simple inverse fourth power law with the lattice parameter. Small variations of the lattice parameter of a crystal may induce important variations of its elastic constants. For example, C33 of graphite (corresponding to the Young's modulus parallel to the hexagonal $c$ axis) depends strongly on the temperature due to interlayer thermal expansion[4] .The Young's modulus of a CNT is therefore related to the $s p^{2}$ bond strength and should equal that of a graphene sheet when the diameter is not too small to distort the $\mathrm{C}-\mathrm{C}$ bonds significantly [11].

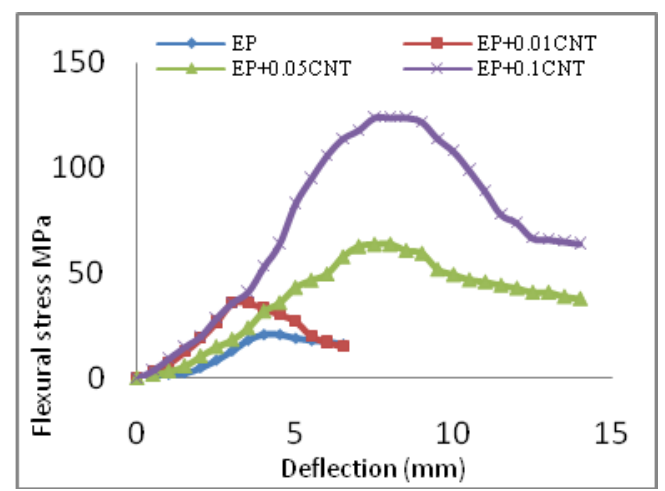

Fig :(1) Flexural stress curve for EP Composites

Table (1) Values of Flexural modulus, Maximum deflection at Max.stress for Epoxy composites.

\begin{tabular}{|c|c|c|c|}
\hline Specimen Type & $\begin{array}{c}\text { Max.flexural } \\
\text { stress(MPa) }\end{array}$ & $\begin{array}{c}\text { Max.deflection } \\
\text { at } \\
\text { max.stress(mm) }\end{array}$ & $\begin{array}{c}\text { Flexural } \\
\text { modulus } \\
\text { E(MPa) }\end{array}$ \\
\hline EP & 20.8 & 3.7 & 23 \\
\hline
\end{tabular}




\begin{tabular}{|c|c|c|c|}
\hline EP+0.01\%CNT & 35.5 & 3.0 & 29 \\
\hline EP+0.05\%CNT & $\mathbf{6 4}$ & 7.5 & 34 \\
\hline
\end{tabular}

\section{2- Tensile test :-}

The samples with specific size of composites have been prepared according to the requirements of tensile test (ANSI/ASTM D638) [9]. The results of tensile strength and tensile modulus were shown in Fig(2). In this study we found epoxy resin matrix with carbon Nano tube .both the tensile strength and tensile modulus of composites increase with the increase of carbon nanotube. In this study, $0.1 \%$ carbon nanotube addition has the best effect on the mechanical properties of the matrix. Network structure was formed, which can take more mechanical loading from the matrix when the matrix is under stress. This means that when the applied loading is over the elastic deformation stress, the carbon nanotubes have a stress transfer \begin{tabular}{|c|c|c|c|}
\hline EP+0.1\%CNT & 124 & 7.5 & 48 \\
\hline
\end{tabular}

effect [12], which can enhance the strength of the resin matrix. The elongation values for epoxy and all composites $\mathrm{CNT}_{\mathrm{S}} / \mathrm{EP}$ (58, 22.8, 11.4, and 10.7$) \%$ respectively shown in table (2).

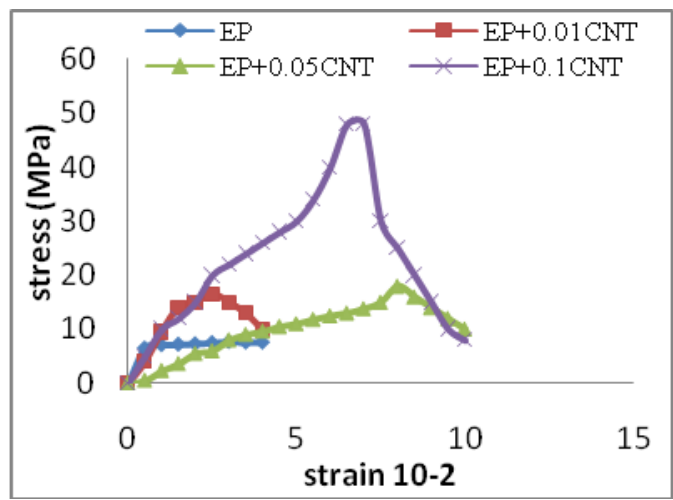

Fig: (2) Tensile stress -strain for epoxy composites

Table (2) Values of Tensile modulus, Tensile strength, Elong at yield, Max. Force and Elongation for Epoxy composites.

\begin{tabular}{|c|c|c|c|c|c|}
\hline $\begin{array}{c}\text { Specimen } \\
\text { Type }\end{array}$ & $\begin{array}{c}\text { Tensile } \\
\text { modulus(MPa) }\end{array}$ & $\begin{array}{c}\text { Tensile } \\
\text { strength(MPa) }\end{array}$ & $\begin{array}{c}\text { Elong } \\
\text { at } \\
\text { yield\% }\end{array}$ & Max.force $(N)$ & Elongation\% \\
\hline EP & 21 & 7.9 & 5.44 & 291.5 & 58 \\
\hline EP+0.01CNT & 23 & 16 & 7.6 & 341.5 & 22.8 \\
\hline EP+0.05CNT & 28 & 18 & 7.73 & 436.5 & 11.4 \\
\hline EP+0.1CNT & 72 & 48 & 7.0 & 670 & 10.7 \\
\hline
\end{tabular}

\section{3- Hardness test :-}

The hardness was increased and the reason for increased hardness values Due to an overlap and stacking, which reduces the movement of polymer molecules, which lead to increase the resistance of material to scratch, cut, and becoming more resistance to plastic deformation, Hardness of materials depended on the type of forces that bind between atoms in the material. The Strong linkages at the interface between phase's Nano carbon and epoxy result to increase the coherence of the mixture, which results a closed working to increase the hardness as shown in Table (3).
Table (3) Values of Hardness values for Epoxy Composites.

\begin{tabular}{|l|l|}
\hline Specimen Type & ShoreD \\
\hline EP & 60.2 \\
\hline EP+0.01CNT & 81.5 \\
\hline EP+0.05CNT & 82.1 \\
\hline EP+0.1CNT & 84.2 \\
\hline
\end{tabular}

\section{Conclusion:-}

Epoxy composites filled with a little wt. $(0.01,0.05$, and 0.1$) \% \mathrm{CNT}$ yield better mechanical properties than pure resin samples due to high strength carbon Nano tube. 


\section{References:-}

1- Ajayan P, Schadler L.S and Braun P.V, 2003 "Nanocomposite science and technology"(verlag :wiley$\mathrm{VCH})$,P. 96.

2- Cooper C. A, Young R. J and Halsall M.,2000 "Mechanical properties of carbon nanotube", Appl. Sci. \& Manuf. Comp., Part A: 32(5): 401.

3- Bokobza L. 2007" Mechanical properties and interfacial characteristics of carbon nanotube reinforced epoxy " J.Appl. poly. Sci.,48(15): 4907.

4- Smutisikha B.,2010"Dispersion and reinforcing mechanism of carbon nanotubes in epoxy Nanocomposites" , Bull. Mater. Sci.,33(1): 27-31 .

5- Allaoui A., Bai S., Chengh M. and Baij B.,2002"Mechanical and electrical properties of a MWNT/ epoxy composite", Comp. Sci. Technol.,62(15):55

6- Schadler L.S. ,Giannaris S. C., and Ajayan P. M.,1998" Load transfer in carbon nanotube/epoxy composites, J.Appl. Phys., 73(26): 3842-3 844.

7- Breton Y., Sarmot G. D. and Salvetat J. P., 2004"Mechanical properties of multiwall carbon nanotubes/epoxy composites: influence of network morphology", J.Carbon,42(2):323-329

8-Osama N.N.,2009 " Effect of carbon nanotube on the properties of liquid crystal),ph.D, thesis, University of Baghdad, College of Science, Department of Physics.

9-Annual book of ASTM Standard vol.08.01, 1989.

10- Annual book of ASTM Standard vol.03.01,1984.

11- Bal J. B.,2003" Evidence of the reinforcement role of chemical vapour deposition multi-walled carbon nanotubes in a polymer matrix" J. Carbon, 41(13): 1325 1328.

12-Qi H.J. ,Joyce K. and Boyce M.C.,2006" Durometer hardness and the stress-strain behavior of elastomeric materials", J. Rub. Chem. Technol., 76(2): 419-435.

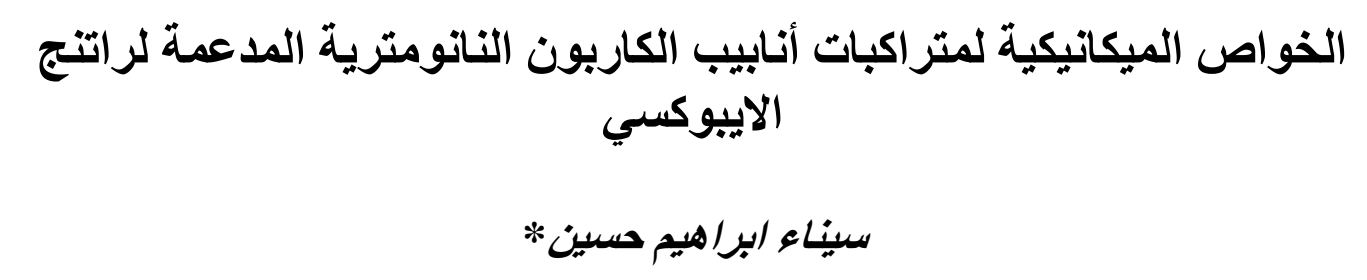

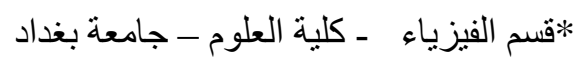

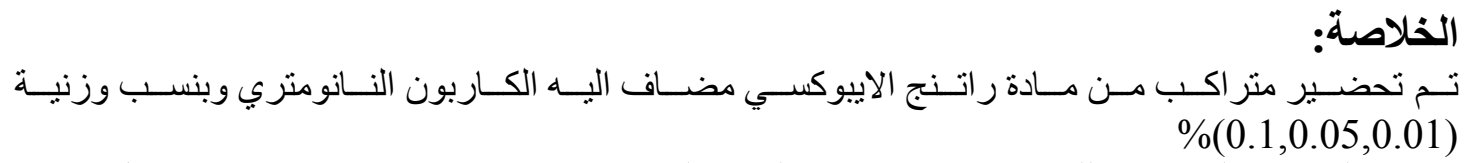

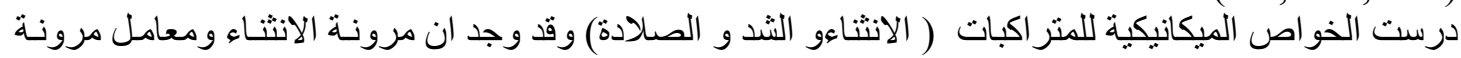

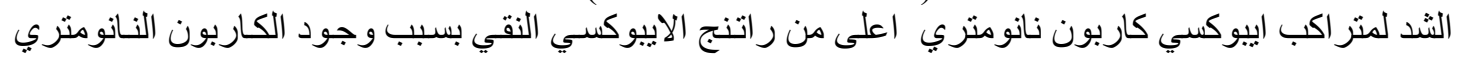

$$
\begin{aligned}
& \text { ذبي الخواص الميكانيكية العالية. }
\end{aligned}
$$

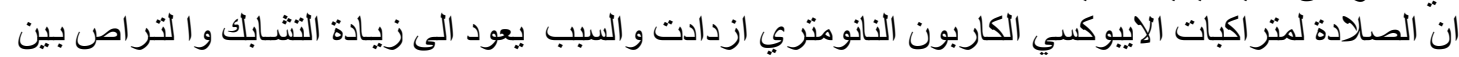

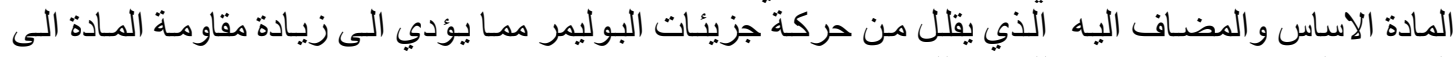

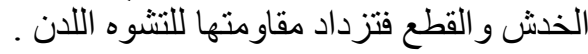


